\title{
Hawthorn (Crataegus Oxyacantha) Extract in the Drinking Water of Broilers on Growth and Incidence of Pulmonary Hypertension Syndrome (PHS)
}

\section{-Author(s)}

\section{Ahmadipour B \\ Kalantar $\mathrm{M}^{1, \text { II }}$ \\ Hosseini SM"I \\ Yang LG'II \\ Kalantar $\mathrm{MH}^{\mathrm{IV}}$ \\ Raza SHAv \\ Schreurs NMvi}

Department of Animal Science, Shahrekord University, 88186-34141, Shahrekord, Iran

" Department of Animal Science, Qom's Agricultural Research Center, Agricultural Research, Education and Extension Organization, Jihad-e-Keshavarzi Ministry, Tehran, Iran

III Key Laboratory of Agricultural Animal Genetics, Breeding and Reproduction, Education Ministry of China, College of Animal Science and Technology, Huazhaong Agricultural University, Wuhan, Hubei, China 430070.

Iv Student Research Committee, Arak University of Medical Science, Arak, Iran

$\checkmark$ College of Animal Science and Technology, Northwest A\&F University, Yangling 712100, Shaanxi, China.

vi Institute of Veterinary, Animal and Biomedical Sciences, Massey University, Private Bag 11222, Palmerston North 4442 , New Zealand.

\section{Mail Address}

Corresponding author e-mail address

Behnam Ahmadipour

Department of Animal Science, Shahrekord University, Shahrekord 88186-34141, Iran Tel: $\quad$ +983814424402×2472

Email: behnam.ahmadipour@gmail.com

\section{ABSTRACT}

Hawthorn extract has been used for ameliorating cardiac disorders and pulmonary hypertension. Flavonoids and oligomeric proanthocyanidins are considered to be responsible for the positive health effects of hawthorn extract. The effect of Hawthorn extract in the water supply on feed intake, growth, carcass traits, internal organ weight, cardiac indices, the concentration of serum proteins and the incidence of pulmonary hypertension syndrome was evaluated in broiler chickens. At one day-of-age, 225 chickens were assigned to one of three experimental groups where $0,0.1$ and $0.2 \mathrm{ML}$ of hawthorn extract was added per one liter of drinking water. Feed intake, live weight gain and carcass weight increased when hawthorn extract was included in the drinking water at a level of 0.1 and $0.2 \mathrm{ML} /(p<0.05)$. Compared to no extract, the addition of Hawthorn extract in the drinking water $(p<0.05)$ reduced the proportion of the body attributed to abdominal fat, liver and heart $(p<0.05)$, and decreased the percentage of birds that died or showed clinical symptoms of pulmonary hypertension syndrome $(p<0.05)$. Serum protein concentration was $(p<0.05)$ higher in chickens that received the hawthorn extract in the drinking water compared to no addition of extract in the drinking water. Hawthorn extract has shown potential for use as a herbal medicine to aid in the prevention of physiological cardiac disorders and pulmonary hypertension in chickens.

\section{INTRODUCTION}

Ascites as a result of pulmonary hypertension syndrome (PHS) and its subsequent physiological disorders lead to mortality and slow growth of broiler chickens especially at high altitude areas with low oxygen pressure (Ahmadipour et al., 2015). Intensive genetic selection for growth rate in broiler chickens has created a situation where the development of the heart and lung is unsynchronized, increasing the sensitivity of broilers to PHS (Sharifi et al., 2015). Advanced pulmonary hypertension and right ventricular failure (RVF) are the final impacts of hypoxia and vasodisorders which leads to ascites and PHS (Wideman, et al., 2013).

Hawthorn (Crataegus oxyacantha) is a member of the Rosaceae family which grows in Asia and other parts of the world (Chang et al., 2002). Excluding the fruit, parts of this medical plant are traditionally used to treat cardiac disorders and cardiovascular problems and used as antihypertensive or antiatherosclerotic agent (Chang et al., 2007). Other positive implications of hawthorn extract have included improving blood circulation, elimination of blood stasis, improved recovery after heart failure and myocardial injuries, and amelioration of hypertension, arrhythmia and inflammation (Chen et al., 1998; Kao et al., 2005; Brixius et al., 2006). The most important chemical constituents in Hawthorn extract are flavonoids and oligomeric proanthocyanidins (OPCs) which are present at a concentration of 1-3\% of the dry matter (Chang et al., 
Ahmadipour B, Kalantar M, Hosseini SM, Yang LG, Kalantar MH, Raza SHA, Schreurs NM
Hawthorn (Crataegus Oxyacantha) Extract in the Drinking Water of Broilers on Growth and Incidence of Pulmonary Hypertension Syndrome (PHS)
2002; Kao et al., 2005; Barros et al., 2011; Kirakosyan et al., 2003). Other bioactive components which have been found at varying concentrations in hawthorn extracts include: triterpene acids (Kao et al., 2007), organic acids (Liu et al., 2011), sterols, and cardioactive amines (Long et al., 2006). Mostly, hawthorn extract is recognized for its flavonoid and OPC content (Long et al., 2006; Surai et al., 2014) and these compounds reported to have several pharmacological effects (Kirakosyan et al., 2003; Chang et al., 2007).

Because the bioactive compounds in Crataegus oxyacantha have known antioxidant activity with positive pharmacological effects and in particular the capacity to moderate serological and immunological parameters and mediate the negative effects of PHS, the objectives of the present study were to examine the effects of different levels of Hawthorn extract in drinking water (HE) of broiler chickens raised in high altitude conditions in respect to the incidence of PHS and associated physiological disorders.

\section{MATERIALS AND METHODS}

\section{Birds and experimental facility}

This experiment was performed in the experimental facility of Shahrekord University, Iran in accordance with the recommendations in the Guide for the Care and Use Committee of Shahrekord University. The effect of Hawthorn extract in the water supply on feed intake, growth, carcass traits, internal organ weight, cardiac indices, incidence of pulmonary hypertension syndrome and the concentration of serum enzymes and proteins was evaluated in the reared broiler chickens. A total of 225 unsexed broiler chicks (Ross 308) were raised under commercial conditions according to Ross 308 broiler management manual (2009) for a 42-day experimental period. At one-day of age the birds were assigned to one of 15 floor pens. The birds had an average body weight of $702 \pm 16 \mathrm{~g}$. The birds were reared at high altitude $(2,100 \mathrm{~m}$ above sea level) and the temperature of the experimental shed was set at about $32^{\circ} \mathrm{C}$ for the first week then reduced to $29^{\circ} \mathrm{C}$ for week 2 to 4 , and finally fixed at $22^{\circ} \mathrm{C}$ until the end of the trial. All birds had free access to feed and water and provided with $23 \mathrm{~h} \mathrm{light}$ and $1 \mathrm{~h}$ dark throughout the trial.

\section{Treatments}

For all experimental groups the diet was based on corn and soybean meal formulated and balanced for nutrients for starting (1-3 weeks of age) and growing (3-6 weeks of age) periods according to the recommendations for broiler chickens (National
Research Council 1994). Treatments were prepared by adding 0, 0.1 and $0.2 \mathrm{ML}$ of Hawthorn (Crataegus oxyacantha) extract per liter of drinking water. The 0 $\mathrm{ML} / \mathrm{L}$ treatment was the control group in this experiment. According to the manufacturer, the Hawthorn extract used contained biologically active flavonoid compounds (polyphenols) such as anthocyanidins and proanthocyanidins. Each ML of Hawthorn extract (IranDarouk Pharmacy Co, Iran, Tehran, Production Code: 3067-88-02) contained $2.5 \mathrm{mg}$ of total flavonoids compounds in form of hyperoside.

\section{Measurements}

Feed intake (FI), average daily gain (ADG) and feed conversion ratio ( $F C R$ ) were calculated as a daily mean for the 42-day period. At the end of the trial, 10 birds per treatment were selected for blood sampling and processing. The selected birds had body weights within approximately $5 \%$ of the average pen body weight. Blood samples ( $3 \mathrm{ML}$ ) were collected from the brachial vein and centrifuged at $2500 \mathrm{~g}$ for $10 \mathrm{~min}$ to obtain sera. Serum samples were used for the determination of serum enzyme concentration including aspartate amino transferase, alanine amino transferase and alkaline phosphatase. Serum protein concentrations were also determined including total protein, albumin and globulin using an auto-analyser (Model Biotecnica BT-3000, Biotecnica Instruments SpA, Germany).

After the blood collection, the selected birds were euthanized and body weight, hot carcass weight, breast, thigh, liver, heart and abdominal fat weights were obtained. For calculating the right-to-total ventricular weight ratio (RV: TV ratio), the heart was also dissected and the ventricles weighed. The RV:TV is an important index for evaluating pulmonary hypertension. Pulmonary hypertension is said to be evident when the RV:TV is greater than 0.25 (Ahmadipour et al., 2015).

\section{Statistical analysis}

Results were analyzed using GLM of the SAS (2007) software. Data were subjected to a nested design due to potential sampling effects within pens. The statistical model used for growth traits without sampling effects was $Y_{i j}=\mu+T_{i}+e_{i j}$. For carcass traits, organ weights and blood parameters which had sampling effects, the model was $Y_{i j k}=\mu+T_{i}+e_{i j}+\varepsilon_{i j k}$. In these models, $Y_{i j}$ and $Y_{i j k}$ are observations; $\mu$ is the general mean; $T_{i}$ is the effect for being in treatment $\mathrm{i} ; \mathrm{e}_{\mathrm{ij}}$ is random error; and $\varepsilon_{\mathrm{ijk}}$ is sub sampling error. Significance was considered to occur when $p<0.05$ and means were separated by Duncan's multiple range test. 
Ahmadipour B, Kalantar M,

Hosseini SM, Yang LG, Kalantar MH,

Raza SHA, Schreurs NM

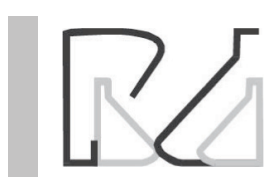

\section{RESULTS}

Effects of different levels of Hawthorn extract on chicken daily growth performance are shown in Table 1. Feed intake, ADG and FCR $(p<0.05)$ improved when Hawthorn extract was included in drinking water at a level of 0.1 and $0.2 \mathrm{ML}$ throughout the trial.

Table 1 - Effects of Hawthorn extract in drinking water on mean growth performance of Ross 308 broiler chickens

Concentration of hawthorn extract in drinking water $(\mathrm{ML} / \mathrm{L})$

\begin{tabular}{lcccc}
\hline Item & 0 & 0.1 & 0.2 & SEM \\
\hline FI (g/bird/day) & $94.82^{\mathrm{b}}$ & $97.60^{\mathrm{a}}$ & $96.61^{\mathrm{ab}}$ & 1.35 \\
ADG (g/bird/day) & $48.74^{\mathrm{b}}$ & $53.33^{\mathrm{a}}$ & $54.59^{\mathrm{a}}$ & 0.98 \\
FCR (g/g) & $1.95^{\mathrm{a}}$ & $1.83^{\mathrm{b}}$ & $1.77^{\mathrm{c}}$ & 0.03 \\
\hline
\end{tabular}

Superscripts in the same row with different letters are significantly different $(p<0.05)$. $\mathrm{Fl}=$ Feed Intake; $\mathrm{ADG}=$ Average Daily Gain; FCR=Feed Conversion Ratio.

Live weight and hot carcass yield was higher and the proportion of abdominal fat in the body weight was lower in broilers that had 0.1 and $0.2 \mathrm{ML} / \mathrm{L}$ Hawthorn extract in the drinking water compared to the control group ( $p<0.05$; Table 2).

Table 2 - Effect of Hawthorn extract in the drinking water on carcass traits of Ross 308 broiler chickens ${ }^{1}$

\begin{tabular}{lcccc}
\hline & \multicolumn{4}{c}{$\begin{array}{c}\text { Oncentration of hawthorn extract } \\
\text { in drinking water (ML/L) }\end{array}$} \\
\hline $\begin{array}{l}\text { Item (\% of body weight } \\
\text { unless noted) }\end{array}$ & 0 & 0.1 & 0.2 & SEM \\
\hline Live body weight (gram) & $2101.3^{\mathrm{b}}$ & $2152.5^{\mathrm{a}}$ & $2260.1^{\mathrm{a}}$ & 44.48 \\
Hot carcass yield & $77.83^{\mathrm{b}}$ & $80.73^{\mathrm{a}}$ & $80.77^{\mathrm{a}}$ & 1.16 \\
Breast yield & 35.27 & 35.05 & 36.35 & 0.87 \\
Thigh yield & 30.21 & 30.54 & 30.22 & 0.45 \\
Abdominal fat & $1.39^{\mathrm{a}}$ & $1.14^{\mathrm{b}}$ & $1.05^{\mathrm{b}}$ & 0.10 \\
\hline
\end{tabular}

Superscripts in the same row with different letters are signficantly different $(p<0.05)$.

'Each mean represents values from 10 replicates.

The percentage that the heart and liver comprised of the body weight was lower and the percentage as spleen and bursa of fabricus was greater in broilers
Hawthorn (Crataegus Oxyacantha) Extract in the Drinking Water of Broilers on Growth and Incidence of Pulmonary Hypertension Syndrome (PHS)

that had 0.1 and $0.2 \mathrm{ML} / \mathrm{L}$ of Hawthorn extract in the drinking water compared to the control group $(p<0.05$; Table 3).

Table 3 - Effect of Hawthorn extract in the drinking water on internal organ weights of Ross 308 broiler chickens ${ }^{1}$

Concentration of hawthorn extract in drinking water $(\mathrm{ML} / \mathrm{L})$

\begin{tabular}{lcccc}
\hline $\begin{array}{l}\text { Item (\% of body weight } \\
\text { unless noted) }\end{array}$ & Control (0) & 0.1 & 0.2 & SEM \\
\hline Heart & $0.83^{\mathrm{a}}$ & $0.71^{\mathrm{ab}}$ & $0.63^{\mathrm{b}}$ & 0.06 \\
\hline Liver & $2.88^{\mathrm{a}}$ & $2.52^{\mathrm{b}}$ & $2.26^{\mathrm{c}}$ & 0.07 \\
Spleen (gram) & $2.44^{\mathrm{b}}$ & $2.66^{\mathrm{b}}$ & $3.15^{\mathrm{a}}$ & 0.17 \\
Bursa of fabricius (gram) & $1.99^{\mathrm{c}}$ & $2.25^{\mathrm{b}}$ & $2.80^{\mathrm{aa}}$ & 0.13 \\
\hline
\end{tabular}

Superscripts in the same row with different letters are significantly different $(p<0.05)$. 'Each mean represents values from 10 replicates.

The broilers that had drinking water with 0.1 and $0.2 \mathrm{ML} / \mathrm{L}$ of Hawthorn extract had a lower RV:TV ratio compared to the control group ( $p<0.05$; Table 4$)$. The birds observed to have pulmonary hypertension and the proportion of birds dying from PHS was lower with the inclusion of Hawthorn extract in the drinking water at levels of 0.1 and $0.2 \mathrm{ML} / \mathrm{L}(p<0.05$; Table 4).

Table 4 - Effect of Hawthorn extract in the drinking water on RV: TV ratio and PHS indices of Ross 308 broiler chickens

Concentration of Hawthorn extract in drinking water (ML/L)

\begin{tabular}{lcccc}
\hline & 0 & 0.1 & 0.2 & SEM \\
RV:TV (ratio) & $0.32^{\mathrm{a}}$ & $0.25^{\mathrm{b}}$ & $0.22^{\mathrm{b}}$ & 0.02 \\
$\begin{array}{l}\text { Birds with Pulmonary } \\
\text { hypertension (\%) }\end{array}$ & $57.3^{\mathrm{a}}$ & $44.7^{\mathrm{b}}$ & $36.8^{\mathrm{c}}$ & 3.85 \\
PHS mortality (\%) & $28.7^{\mathrm{a}}$ & $22.3^{\mathrm{b}}$ & $18.4^{\mathrm{b}}$ & 2.88 \\
\hline
\end{tabular}

Superscripts in the same row with different letters are significantly different $(p<0.05)$. Each mean represents values from 10 replicates.

$\mathrm{RV}: \mathrm{TV}=$ right ventricle to total ventricle weight ratio.

The concentration of AST, ALT and ALP in chickens that had Hawthorn extract in the drinking water at a level of 0.1 and $0.2 \mathrm{ML} / \mathrm{L}$ was lower than the control group ( $p<0.05$; Table 5 ). The AST/ALT ratio between the experimental groups was not different (Table 5).

Table 5 - Effects of Hawthorn extract in the drinking water on serum enzyme concentration of Ross 308 broiler chickens ${ }^{1}$

\begin{tabular}{|c|c|c|c|c|}
\hline $\begin{array}{l}\text { Concentration of } \mathrm{HE} \\
\text { in drinking water }(\mathrm{ML} / \mathrm{L})\end{array}$ & $\begin{array}{l}\text { Aspartate Amino } \\
\text { Transferase }\end{array}$ & Alanine Amino Transferase & Alkaline Phosphatase & $\begin{array}{c}\text { Aspartate Amino Transferase } \\
\text { Alanine Amino Transferase }\end{array}$ \\
\hline 0 & $232.63^{a}$ & $4.26^{a}$ & $2502.51^{a}$ & 54.61 \\
\hline 0.1 & $214.00^{b}$ & $3.56^{b}$ & $2434.14^{a}$ & 60.11 \\
\hline 0.2 & $174.50^{c}$ & $3.02^{c}$ & $2034.26^{b}$ & 57.78 \\
\hline SEM & 6.42 & 0.15 & 101.51 & 3.57 \\
\hline
\end{tabular}

Superscripts in the same column with different letters are significantly different $(p<0.05)$.

'Each mean represents values from 10 replicates. 
Ahmadipour B, Kalantar M, Hosseini SM, Yang LG, Kalantar MH, Raza SHA, Schreurs NM
Hawthorn (Crataegus Oxyacantha) Extract in the Drinking Water of Broilers on Growth and Incidence of Pulmonary Hypertension Syndrome (PHS)
Chickens that received Hawthorn extract in the drinking water at a level of 0.1 and $0.2 \mathrm{ML} / \mathrm{L}$ had a higher concentration of total protein, albumin and globulin than the control group ( $p<0.05$; Table 6).

Table 6 - Effects of Hawthorn extract in the drinking water on serum protein concentration of Ross 308 broiler chickens $^{1}$

\begin{tabular}{lcccc}
\hline $\begin{array}{l}\text { Concentration of } \mathrm{HE} \\
\text { in drinking water }(\mathrm{ML} / \mathrm{L})\end{array}$ & TPr & Albu & Glob & Albu/Glob \\
\hline 0 & $3.84 \mathrm{~b}$ & $2.00 \mathrm{c}$ & $1.84 \mathrm{~b}$ & $1.09 \mathrm{~b}$ \\
0.1 & $4.55 \mathrm{a}$ & $2.27 \mathrm{~b}$ & $2.28 \mathrm{a}$ & $0.99 \mathrm{~b}$ \\
0.2 & $4.85 \mathrm{a}$ & $2.75 \mathrm{a}$ & $2.10 \mathrm{a}$ & $1.31 \mathrm{a}$ \\
SEM & 0.23 & 0.11 & 0.13 & 0.11 \\
\hline
\end{tabular}

Superscripts in the same column with different letters are significantly different $(p<0.05)$. 'Each mean represents values from 10 replicates. $\mathrm{TPr}=$ : Total Protein; Albu=Albumin; Glob=Globulin; Albu/Glob= The ratio of Albumin to Globulin.

\section{DISCUSSION}

Improvements were observed in growth ( $\mathrm{Fl}, \mathrm{ADG}$ and FCR) and carcass (live body weight and hot carcass yield) characteristics when Hawthorn extract was included in the drinking water at 0.1 and $0.2 \mathrm{ML} / \mathrm{L}$ for broilers raised under high altitude conditions. The improved growth performance are likely to be a consequence of the naturally occurring polyphenols (flavonoids) and oligomeric proanthocyanidins (OPCs) in the Hawthorn (Crateagus oxyacantha) extract. Polyphenols and flavonoids have been noted to be promotors of growth due to their anti-oxidative and antibacterial properties (Barros et al., 2001; Surai et al., 2014).

Abdominal fat deposition and liver growth was reduced when chickens consumed Hawthorn extract in the drinking water. Hawthorn extract has a lipolytic effect which is attributed to flavonoids and OPCs as well as phenolic compounds (Rajendran et al., 1996). Lipid-lowering effects of bioactive compounds such as flavonoids have been well demonstrated (Rajendran et al., 1996; Anila et al., 2002). Because the liver in the chicken is the major organ of lipogenesis (Sharifi et al., 2015) the reduced liver weight reflects lower lipogenic activity.

An increased spleen weight is considered an indicator of the body combating and trying to ward against diseases or stresses (Corrier et al., 1990; Rezaei et al., 2014). Medicinal plant extracts especially flavonoid extracts inhibit the growth and proliferation of pathogenic micro-organisms and protect the gut epithelium directly (Nofrarias et al., 2006). The reduced incursion of pathogens and microbes into the body which plant extracts such as Hawthorn provides, modify the weight and activity of immune organs such as the bursa of fabricius and thymus indirectly (Rezaei et al., 2014; Fathiet al., 2015).

Hawthorn extract seems to control heart hypertrophy and particularly right ventricular hypertrophy which results in a lower heart weight. The birds of the control group with a RV:TV ratio of 0.32 can be considered to be in a preascitic condition and this was prevented when birds consumed Hawthorn extract in the drinking water because the RV:TV was at 0.25 or below. The effect of the Hawthorn extract on preventing mortality via PHS and Ascites was evident.

Positive pharmacological effects of hyperoside, which is the bioactive constituent of Hawthorn include potent antioxidant and free radical scavenging activities to prevent oxidative damage caused by pulmonary hypertension or cardiovascular injuries (Chang et al., 2007; Barros et al., 2011).

One of the most important ways to diagnose pathological conditions in birds is the serum enzyme activity (Senanayake et al., 2015). Alkaline phosphatase is one of the serum enzymes involved in dephosphorylation and active in the organs of liver, intestine and bones, but the highest activity of this enzyme is in the alkaline environment of the liver. Often, increased levels of alkaline phosphatase indicates liver damage (Sorbi et al., 1999; Senanayake et al., 2015). Higher serum levels in ascitic broilers indicate a higher tissue peroxidation rate which results in liver, lung and heart damage. The Hawthorn extract reduced the serum alkaline phosphatase and it has been reported that the flavonoids and oligometric proanthocyanidins such as those found in Hawthorn have protective effects on hepatocytes by scavenging the free radicals in the body.

Aspartate aminotransferase and alanine aminotransferase are liver enzymes which are released into the blood stream when there is liver damage. These two serum enzymes are the main indicators to diagnose liver damage. The production of free radicals increases in hypoxic conditions which decreased the potency of body antioxidant systems, which eventually lead to oxidative stress and extensive destruction of cell membranes and damage of internal organs (Janeway et al., 2001). In the hypoxic state prior to ascites in chickens the serum levels of aspartate aminotransferase and alanine aminotransferase increase due to a higher demand for oxygen and this increases the incidence of PHS (Fathi et al., 2015).

Higher total serum protein of the birds that received the Hawthorn extract suggests an improved ability of the hepatocytes to synthesize protein and consequently 
Ahmadipour B, Kalantar M,

Hosseini SM, Yang LG, Kalantar MH,

Raza SHA, Schreurs NM
Hawthorn (Crataegus Oxyacantha) Extract in the Drinking Water of Broilers on Growth and Incidence of Pulmonary Hypertension Syndrome (PHS) improves the physiological and immunological responses to disease or biological stressors (Corrier et al., 1990; Rezaei et al., 2014). Serum globulin concentrations along with immunoglobulin (IgG and IgM) are components of total serum immunoglobulin which guard the body against foreign antigens (Jahanian et al., 2009). Higher serum globulin level in the birds that received Hawthorn extract had a potentially better immune status (Janeway et al., 2001; Jahanian et al., 2009) which is further substantiated by the fact that liver percentage and immune organs (spleen and bursa of fabricius) were heavier for weight in with the birds that had access to the Hawthorn extract. The increased albumin level in this study could have positive effects on the colloidal state of blood as well as capillary permeability, which assists in preventing pulmonary hypertensive birds.

\section{CONCLUSION}

The findings of this study suggests that antioxidants such as those found in Hawthorn help maintain the health and vitality of broiler chicken raised in high altitude zones. The bioactive flavonoids and OPCs in Hawthorn extracts protect against oxidative stress and lipid peroxidation. For commercial broiler chickens consuming Hawthorn extract in drinking water at a concentration between of 0.1 and $0.2 \mathrm{ML} / \mathrm{L}$, free radical production is suppressed, growth and carcass performance is promoted and the serological and immunological characteristics are improved providing an amelioration of pulmonary hypertensive and ascitic chickens.

\section{ACKNOWLEDGMENTS}

The authors are grateful for the financial support of Shahrekord University, Shahrekord, Iran. Authors also thank for technical supports of Animal Science Department of Agricultural Research Center of Qom (QARC), Qom, Iran.

\section{AUTHOR CONTRIBUTIONS}

Behnam Ahmadipour and Majid Kalantar conceived and designed the experiments. Behnam Ahmadipour performed the experiments and wrote the manuscript. Seyed Mahdi Hosseini and Li Guo Yang assisted in analyzing the data. Mohammadhassan Kalantar helped to collect the samples and data. Sayed Haidar Abbas Raza and Nicola M. Schreurs provided constructive suggestions for the discussion and reviewed the manuscript for language usage and grammar.

\section{REFERENCES}

Ahmadipour B, Hassanpour H, Asadi E, Khajali F, Rafiei F, Khajali F. Kelussia odoratissima Mozzaf- A promising medicinal herb to prevent pulmonary hypertension in broiler chickens reared at high altitude. Journal of Ethnopharmacology 2015;159:49-54.

Anila L, Vijayalaksh, NR. Flavonoids from Emblica officinalis and Mangifera indica effectiveness for dyslipidemia. Journal of Ethnopharmacology 2002;79:81-87

Barros L, Carvalho AM, Ferreira IC. Comparing the composition and bioactivity of Crataegus monogyna flowers and fruits used in folk medicine. Phytochemical Analysis 2011;22:181-188.

Brixius K, Willms S, Napp A, Tossios P, Ladage D, Bloch W, et al. Crataegus special extract WS 1442 induces an endothelium-dependent, NOmediated vasorelaxation via eNOS-phosphorylation at serine 1177 Cardiovascular Drugs and Therapy 2006;203:177-184.

Chang Q, Zuo Z, Harrison F, Chow MSS. Hawthorn. Journal of Clinical Pharmacology 2002;42:605-612.

Chang W, Shao Z, Yin J, Mehendale S, Wang C, Qin Y, et al. Comparative effects of flavonoids on oxidant scavenging and ischemia-reperfusion injury in cardiomyocytes. European Journal of Pharmacology 2007;566:58-66.

Chen Z, Zhang ZS, Kwan KY, Zhu M, Ho W, Huang Y. Endotheliumdependent relaxation induced by hawthorn extract in rat mesenteric artery. Life Sciences 1998;6322:1983-1991.

Corrier D, Deloach, J. Evaluation of cell-mediated, cutaneous basophil hypersensitivity in young chickens by an interdigital skin test. Poultry Science 1990;69:403-408.

Fathi M, Nazera ADL, Ebrahim Nezhad Y, Aghdam Shahryar H, Daneshyar M, Tanha, T. The role of oxidative stress in the development of congestive heart failure (CHF) in broilers with pulmonary hypertension syndrome (PHS). Journal Cell and Animal Biology 2015;176:181.

Jahanian R. Immunological responses as affected by dietary protein and arginine concentrations in starting broiler chicks. Poultry Science 2009;88:1818-1824.

Janeway C. Immunobiology. 5th ed. New York: Garland Science; 2001.

Kao E, Wang C, Lin W, Yin Y, Wang C, Tseng T. Anti-inflammatory potential of flavonoid contents from dried fruit of Crataegus pinnatifida in vitro and in vivo. Journal of Agricultural and Food Chemistry 2005;532:430436 .

Kao E, Wang CJ, Lin WL, Chu CY, Tseng TH. Effects of polyphenols derived from fruit of Crataegus pinnatifida on cell transformation, dermal edema and skin tumor formation by phorbol ester application. Food and Chemical Toxicology 2007;45:1795-1804.

Kirakosyan A, Seymour E, Kaufman PB, Warber S, Bolling S, Chang SC. Antioxidant capacity of polyphenolic extracts from leaves of Crataegus laevigata and Crataegus monogyna (Hawthorn) subjected to drought and cold stress. Journal of Agricultural and Food Chemistry 2003;51:3973-3976

Liu P, Yang, B, Kallio H. Phenolic compounds in hawthorn (Crataegus grayana) fruits and leaves and changes during fruit ripening. Journal of Agricultural and Food Chemistry 2011;59:11141-11149.

Long SR, Carey RA, Crofoot KM, Proteau PJ, Filtz TM. Effect of hawthorn (Crataegus oxycantha) crude extract and chromatographic fractions on multiple activities in a cultured cardiomyocyte assay. Phytomedicine 2006;13:643-650 
Nofrarias E, Manzanilla G, Pujols J, Gibert X, Majo N, Segales J, et al. Effects of spray-dried porcine plasma and plant extracts on intestinal morphology and on leukocyte cell subsets of weaned pigs. Animal Science 2006;842:735-2742.

NRC- National Research Council. Nutrient requirements for poultry. $9^{\text {th }}$ rev ed. Washington; 1994.

Rajendran S, Deepalakshmi, PD, Parasakthy, K, Devaraj, H, Devaraj, SN. Effect of tincture of Crataegus on the LDL-receptor activity of hepatic plasma membrane of rats fed an atherogenic diet. Atherosclerosis 1996;123:235-241.

Rezaei M, Kalantar M, Nasr J. Thymus vulgaris L., Glycyrrhiza glabra, and combo enzyme in broiler chickens. International Journal Plant Animal Environmental Sciences 2014;44:18-423.

Senanayake S, Ranasinghe J, Waduge R, Nizanantha K, Alexander A. Changes in the serum enzyme levels and liver lesions of broiler birds reared under different management conditions. Tropical Agriculture Research 2015;264:584-595.
Sharifi MR, Khajali F, Hassanpour H, Pour-Reza J, Pirany N. L-arginine supplementation of reduced-protein diets improves pulmonary hypertensive response in broiler chickens reared at high altitude. British Poultry Science 2015;56:470-476.

Sorbi D, Boynton J, Lindor K. The ratio of aspartate aminotransferase to alanine aminotransferase: Potential value in differentiating nonalcoholic steatohepatitis from alcoholic liver disease. ${ }^{\circ}$ American Journal Gastroenterology 1999;94:1018-1022.

Surai P. Polyphenol compounds in the chicken/animal diet: from the past to the future. Journal of Animal Physiolology and Animal Nutrition 2014;98:19-31.

Wideman RF, Rhoads, DD, Erf GF, Anthony NB. Pulmonary arterial hypertension (PAH, ascites syndrome) in broilers: a review. Poultry Science 2013;92:64-83. 